\title{
DESIGN AND OPTIMAL SYNTHESIS OF COMPLIANT MECHANISMS - AN
}

\section{OPTIMALITY CRITERIA APPROACH}

\author{
G. ARUNKUMAR ${ }^{1}$, S. LAKSHMI SANKAR ${ }^{2}$ \& S. PADMAGIRISAN ${ }^{3}$ \\ ${ }^{I}$ Professor and Head, Department of Mechanical Engineering, Sathyabama University, Chennai, Tamil Nadu, India \\ ${ }^{2}$ Associate Professor, Department of Mechanical Engineering, Sathyabama University, Chennai, Tamil Nadu, India \\ ${ }^{3}$ Adjunct Faculty, Department of Mechanical Engineering, EMBRY-RIDDLE Aeronautical University, Arizona, United States

\begin{abstract}
Compliant mechanisms can be viewed as a single elastic continuum and gain mobility from the deflection of flexible members, rather than links and Joints. Compliant Mechanisms are modeled using the methods of continuum solid mechanics, rather than rigid body kinematics. Structural Optimization techniques can be adopted for compliant mechanism design. The geometric structure of a compliant mechanism and the properties of the material it is made of determine its force and motion transmission capability. Design of compliant mechanisms, then becomes an inverse problem wherein, the geometry of the flexible material continuum for a given material is to be obtained for prescribed force and displacement specifications. Continuous Optimization methods are employed in solving this inverse problem. The unique feature of this design method is that, optimal solutions of the compliant mechanisms can be generated automatically to obtain desired force-deflection behavior. No decisions are made about this physical form of the compliant mechanism at the outset, except specifying the space in which it should fit. The optimization algorithm generates the best solution for a given problem specification. The solutions obtained in this manner have adequate details to generate the manufacturing information automatically, in the form of computer numerically controlled machine code, for macro devices.
\end{abstract}

KEYWORDS: Compliant Mechanisms, Topology Optimization, Optimal synthesis \& Continuum Models

Received: Dec 14, 2017; Accepted: Jan 04, 2017; Published: Feb 20, 2018; Paper Id.: IJMPERDFEB2018151

\section{INTRODUCTION ON DISTRIBUTED COMPLIANCE}

The elastic deformation in a compliant mechanism can be limited only to a small portion as in mechanisms with flexural or notch hinges. Such mechanisms are called lumped compliant mechanisms and they can be analyzed and designed using rigid-body kinematic techniques [1]. On the other hand, if a large portion of the structure deforms as shown in figure is called distributed compliance.

\section{Continuum Models}

If the Deforming structure has a regular geometry such as beam with constant cross-section area or a diaphragm of uniform thickness, analysis and design can be accomplished with simple analytical models such as euler beam theory model and pseudo-rigid-body model [2].

\section{Structural Optimization}

Structural Optimization techniques enable us to design optimum structures systematically [3]. The essence of structural optimization is the economical and efficient use of material in designing a structural component to 
meet certain objectives under some constraints.

\section{Topology Optimization}

Topology Optimization is at the highest level in structural optimisation and is the most general. When we have a design domain, in which, the compliant mechanism has to fit and we want to use only a limited amount of material to create the mechanism, we should consider all possible ways of distributing the material within the domain [4]. Like type synthesis techniques of rigid-link mechanisms, topology Optimisation procedures bring a multitude of possible designs into the hands of a designer [5, 6]. The algorithm of Topology optimisation tool will determine the optimum topology for the design domain. The developments in the last decade have resulted in very efficient design parameterizations that lead not only to optimal topology but also to shape and size simultaneously [7.8].

\section{OPTIMALITY CRITERIA (OC) METHOD}

An optimality criteria (OC) solution method (Figure A2.1) is used for topological optimization [9, 10]. The usual inputs to topology optimization such as the size and shape of the design domain, the location of physical supports, the location and direction of the applied force from the PZT stack, and a limit on the total material resource or volume are required. In addition, the location and direction of the desired actuator output are required [11, 12]. OC methods are well suited for problems with a small number of constraints compared with a number of design variables and are generally more computationally efficient than the mathematical programming methods [13,14]. As there is only one active constraint (the material resource constraint), the $\mathrm{OC}$ method can be used to provide more rapid convergence when compared with the sequential linear programming algorithm $[15,16]$. This shows that the OC method is the suitable method over the other methods as discussed by Kikuchi and Nishiwaki (1998), Belegundu and Chadruparla (1999), Lau and Du (2001), Xu and Ananthasursh (2003), Yin and Ananthasuresh (2003), Pedersen and Anandhasuresh (2006), Rubio and Nishiwaki (2010).

Normally, the topology optimization is carried out using ANSYS topological optimization tool or MATLAB software. This involves the following stages, viz, preprocessor, Solution and Post processor [17, 18].

- Preprocessing: In the topology optimization, first model the design domain, then mesh the design domain, and apply the load and boundary conditions.

- Solution: This is an important stage in the topology optimization of the compliant mechanism. In this stage, the objective function and constraint for the topological optimization should be specified, and then the number of iterations for the topological loop should be specified.

- Post Processing: Plot the optimized topology at different iterations. Optimize the shape manually based on the topology obtained. Model the optimized shape and analyse it for the structural behaviour.

\section{STEPS OF THE OC METHOD}

The OC procedure involves the following steps:

- The nodal deflection field of the structure is obtained using a linear finite-element analysis.

- The design variables are resized on the basis of the OC with a limiting step size of 10 per cent. This step size limit is used to prevent the algorithm from converging in just one iteration. 
- A search direction $\mathrm{S}$ is defined as $\mathrm{A}_{\text {new }}-\mathrm{A}_{\text {old }}$, where $A$ is the vector of design variables.

- A one-dimensional minimization on the variable $\alpha$ is used to find the maximum objective value along the direction $\mathrm{S}$ while constraining the design variables to remain within their bounds.

- By iterative procedure the solution convergence is obtained

These steps carried out to design the complaint amplifier are shown in the Figure 1.

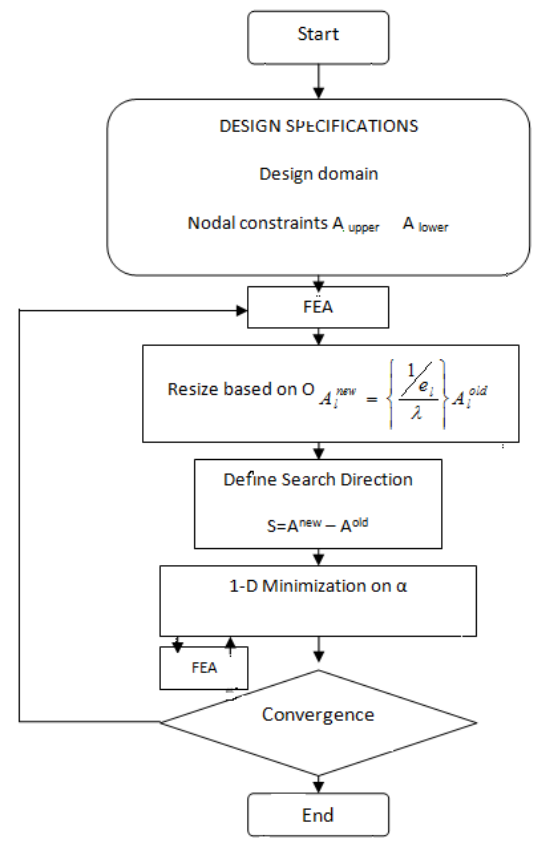

Figure 1: OC Procedure

\section{DESIGN OF COMPLIANT AMPLIFIER FOR THE SPECIFIED OUTPUT DISPLACEMENT}

The compliant amplifier has been designed by topology optimization from a rectangular geometry. The work has been extended to other regular basic geometries. In this design, both Geometric advantage and Mechanical advantage have been considered as objective function [20, 21]. However, in real time applications, it's necessary to obtain a specified output displacement at given location for the given input. The compliant amplifier has been designed using Ansys topology Optimization Tool. Hence the design of compliant amplifier for the specified output displacement under the given input conditions can be attempted using cosmos or Matlab software also.

\section{DESIGN OF A COMPLIANT AMPLIFIER FOR OPERATING A PROPORTIONAL VALVE}

In the field of fluid control applications, the Piezo actuators are widely used. Piezo Injectors based Piezo actuators offer a short response time. It's available in compact size and potentially low cost. Also its used in automotive and aerospace applications. Here compliant amplifier suitable for operating a proportional valve is taken for design.

\section{Input Conditions}

Input conditions are given in the Table 1. 
Table 1: Input Conditions for the Rectangular Design Domain

\begin{tabular}{|l|c|}
\hline Maximum Input force from PZT & $10 \mathrm{~N}$ \\
\hline $\begin{array}{l}\text { Upper limit of design variable } \\
\text { (Cross sectional area of the element) }\end{array}$ & $20 \mathrm{~mm}^{2}$ \\
\hline $\begin{array}{l}\text { Lower limit of design variable } \\
\text { (Cross sectional area of the element) }\end{array}$ & $0.1 \mathrm{~mm}^{2}$ \\
\hline
\end{tabular}

\section{Output Requirements}

The displacement which is required to fully open the proportional valve is $7.8 \mathrm{~mm}$. So, the output displacement from the compliant mechanisms integrated with piezo actuators to be designed is $7.8 \mathrm{~mm}$, when the maximum input force is applied.

\section{Problem Specifications}

The Problem specification along with material Properties are given in the Tables2.

\section{Table 2: Problem Specifications for the Rectangular Design Domain}

\begin{tabular}{|l|c|}
\hline Basic design domain (Rectangular domain) & $500 \mathrm{~mm} \times 400 \mathrm{~mm}$ \\
\hline Young's modulus & $180 \mathrm{GPa}$ \\
\hline Poisson's ratio & 0.30 \\
\hline Maximum input force & $10 \mathrm{~N}$ \\
\hline Upper limit of design variable & $20 \mathrm{~mm}^{2}$ \\
\hline Lower li Lower Limit of design variable & $0.1 \mathrm{~mm}^{2}$ \\
\hline Output displacement at output port & $7.8 \mathrm{~mm}$ \\
\hline
\end{tabular}

\section{METHOD OF SOLUTION}

Optimality Criteria (OC) method will provide the quick convergence so it has been used in this analysis. In the design domain, the boundary conditions specified as the left side of the design domain fixed completely and a point load is applied at the bottom face. The material property, the domain dimensions and design variable are given subsequently. Figure 2(a) shows the design domain with boundary conditions. The discretized domains with the nodal constraints are shown in Figure 2(b). The incremental iterations for obtaining the optimal topology of the mechanism are shown in Figures 2(c) to 2(h). The compliance variation is represented in Figure 2(i) and the displacement plot of the final topology is represented in Figure 2(j).

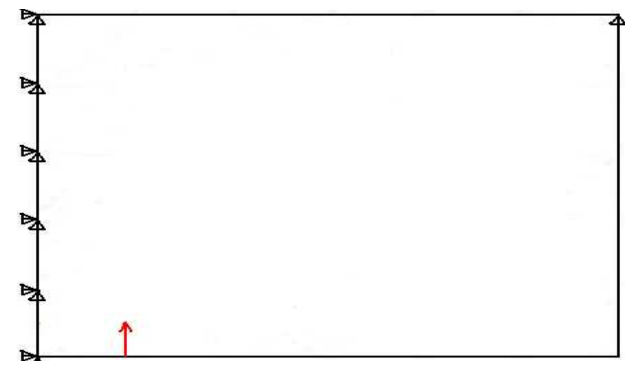

(a) Design Domain

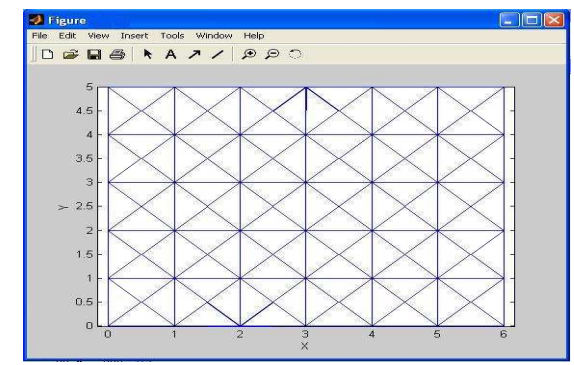

(b) Meshed Design Domain 


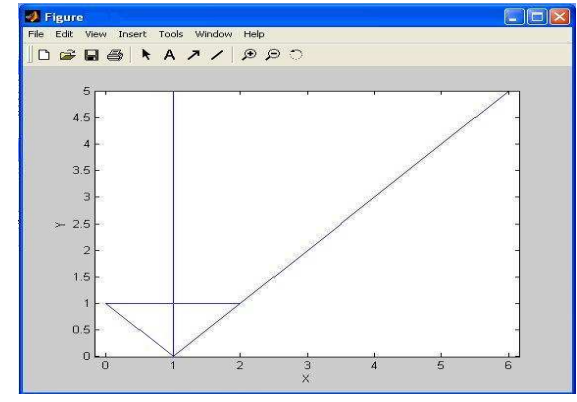

(c) Topology after 20 Iterations

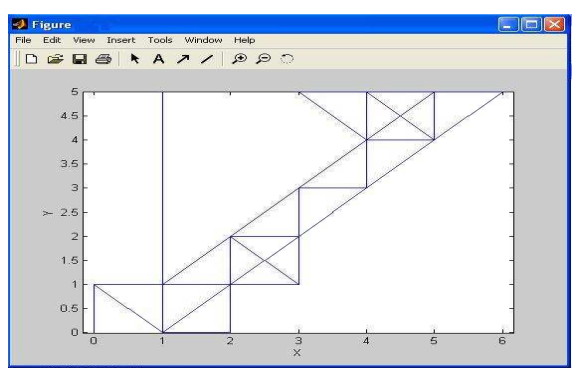

(e) Topology after 60 Iterations

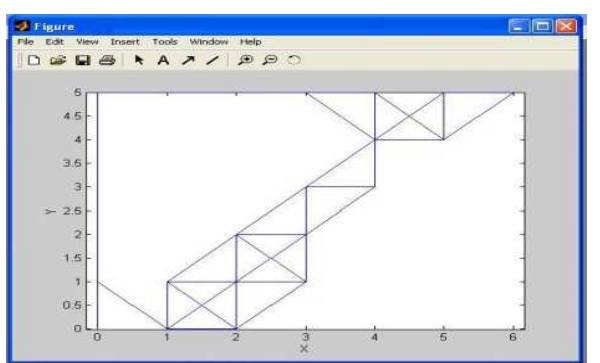

(g) Topology after 100 Iterations

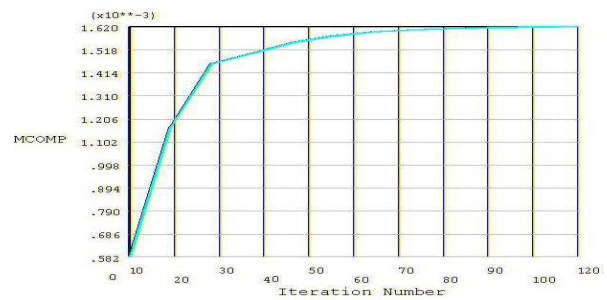

(i) Compliance Variance

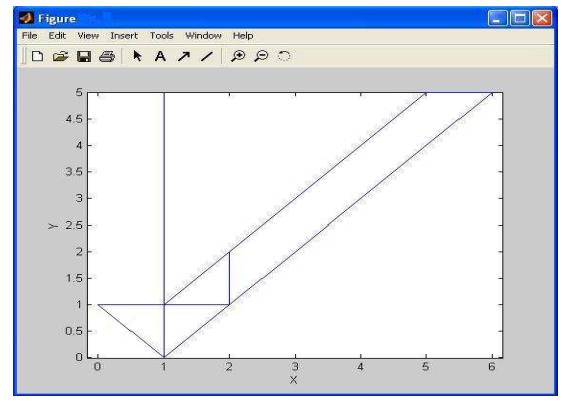

(d) Topology after 40 Iterations

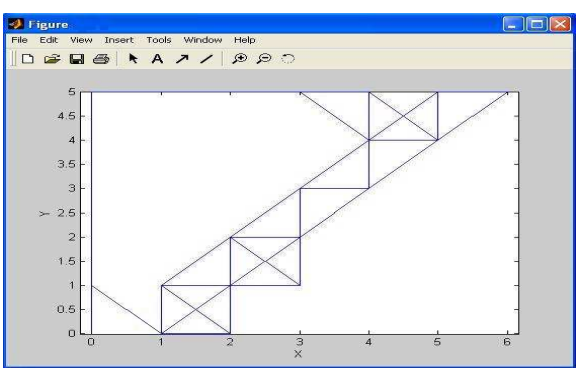

(f) Topology after 80 Iterations

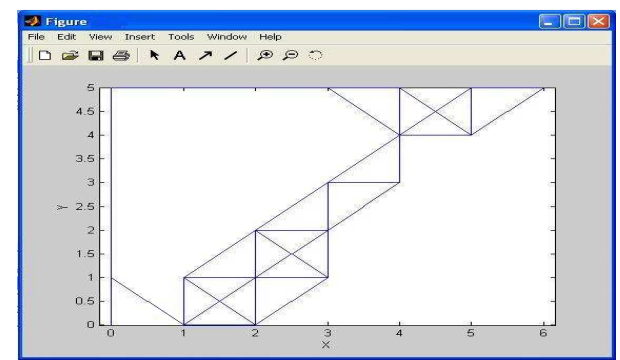

(h) Topology after 120 Iterations

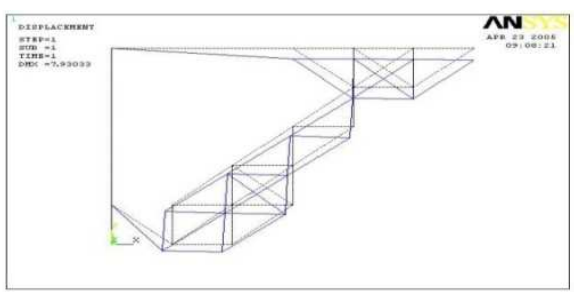

(j) Displacement Plot

Figure 2: (a-j) Iterations of Topology Optimization of Compliant Amplifier

\section{RESULTS OF THE NUMERICAL EXPERIMENT}

- The input displacement given by PZT to compliant mechanism is $2.5 \mathrm{~mm}$ corresponding to input force.

- The output displacement obtained at the output port of compliant mechanism is $7.80 \mathrm{~mm}$.

- $\quad$ The Geometrical Advantage (GA) of the optimized topology is 2.5.

- $\quad$ The Geometrical Advantage obtained from ANSYS is 2.37.

- $\quad$ The Mechanical Advantage (MA) obtained is 0.50. 


\section{CONCLUSIONS}

The final design of compliant amplifier obtained using Topology Optimization was analyzed. The output displacement obtained is $7.80 \mathrm{~mm}$. The amplified output displacement is used to operate the proportional value, and used to operate a micro vibratory chute also.

\section{ACKNOWLEDGMENT}

The author acknowledges Sathyabama University for providing the facilities for the Numerical Experiments

\section{REFERENCES}

1. Howell L. L. and Midha A. (1995), 'The Effects of a Compliant Workforce on the Input/ Output Characteristics of Rigid Link Toggle Mechanisms', Journal of Mechanism and Machine Theory, Vol. 30, No. 6, pp. 801-810.

2. Howell L. L. (2001), 'Compliant Mechanisms', John Wiley \& Sons Inc, pp. 1-15.

3. Anandhasuresh G. K. and Saxena A. (2000), 'On an Optimal Property of Compliant Topologies', Journal of Structural Multidisc Optimization, Vol. 19, pp. 36-49.

4. Belegundu A. and Chadruparla T. (1999), 'Optimization Concepts and Applications in Engineering', Upper Saddle River, New Jersey, Prentice Hall Publications.

5. Bendsoe M. P. and Kikuchi N. (1998), 'Generating Optimal Topologies in Structural Design Using a Homogenization Method', Journal of Computer Methods in Applied Mechanics and Engineering, Vol. 71, pp. 197-224.

6. Bruns T. E. and Tortoelli D. A. (2001), 'Topology Optimization of Nonlinear Elastic Structures and Compliant Mechanisms', Journal of Computer Methods in Applied Mechanics and Engineering, Vol. 190, pp. 3443-3459.

7. Canfield S. and Fracker M. (2000), 'Topology Optimization of Compliant Mechanical Amplifiers', Journal of Structural Multidisc Optimization, Vol. 20, pp. 269-279.

8. Deepak R, Dinesh M, Sahu D. K. and Ananthasuresh G. K. (2009), 'A Comparative Study of the Formulations and Benchmark Problems for the Topology Optimization of Compliant Mechanisms', Journal of Mechanisms and Robotics, Vol.1, pp.215-222.

9. Dong Xu and Ananthasuresh G. K. (2003), 'Freeform Skeletal Shape Optimization of Compliant mechanisms', Journal of Mechanical Design, Vol. 125, pp. 253-261.

10. Fracker M. and Abdalla M. M. (2003), 'Maximum Energy-Efficiency Compliant Mechanism Design for Piezoelectric Stack Actuators', ASME International Mechanical Engineering Congress, Washington, D. C., pp. 1-9.

11. Frecker M. and Kota S. (1997), 'Topological Synthesis of Compliant Mechanisms Using Multi-Criteria Optimization', Journal of Mechanical Design, Transaction of ASME, Vol. 119, pp. 238-245. 100

12. Hetric J. A. and Kota S. (1999), 'An Energy Formulation for Parametric Size and Shape Optimization of Compliant Mechanisms', ASME Journal of Mechanical Design, Vol. 121, pp. 229-234.

13. Jensen B. D. and Howell L. L. (1999), 'Design of Two-Link, In-Plane, Bistable Compliant Micro-Mechanisms', ASME Journal of Mechanical Design, Vol. 121, pp. 416-423.

14. Kikuchi N. and Nishiwaki S. (1998), 'Design Optimization method for Compliant Mechanisms and Material Microstructure', Journal of Computer Methods in Applied Mechanics and Engineering, Vol. 151, pp. 401-417. 
15. Lau G. K., Du H. and Lim M. K. (2001), 'Use of Functional Specifications as Objective Functions in Topological Optimization of Compliant Mechanism', Journal of Computer Methods in Applied Mechanics and Engineering, Vol. 190, pp. 4421-4433.

16. Lu K. J. and Kota S. (2002), 'Compliant Mechanism Synthesis for Shape-Change Application: Preliminary results', Journal of Smart Structures and Materials, Vol. 4693, pp. 161-172.

17. Mankame N. D. and Ananthasuresh G. K. (2004), 'Topology Synthesis of Electrothermal Compliant Mechanisms using Line Elements', Journal of Structural Multidisc Optimization, Vol. 26, pp. 209-218.

18. Nishiwaki S., Frecker M. and Kikuchi N. (1998), 'Topology Optimization of Compliant Mechanisms Using the Homogenization method', International Journal of Numerical Methods and Engineering, Vol. 42, pp. 535-559.

19. Pedersen C. B. W and Anandhasuresh G. K. (2006), 'Design of a Compliant Mechanism to Modify an Actuator Characteristic to Deliver a Constant Output Force', Journal of Mechanical Design, Vol.128, pp.1101-1112.

20. Saxena A. and Ananthasuresh G. K. (2003), 'A Computational Approach to the Number of Synthesis of Linkages', Journal of Mechanical Design, Transactions of ASME, Vol. 125, pp. 110-118.

21. Arunkumar, G., Srinivasan, P. S. S. (2006),'Design of displacement cements amplifying compliant mechanisms with integrated strain actuator using topology optimization” proceedings of the Institution of Mechanical Engineers, Part C: Journal of Mechanical Engineering Science Volume: 220 issue: 8, pp.1219-1228. 
